\title{
Epidemiologia intoxicațiilor cu antidiabetice orale la copii și adolescenți - studiu pe 4 ani într-un centru antitoxic pediatric
}

\author{
Dana Adriana Dăsculțu', Elena Mădălina Petran ${ }^{1,2}$, Coriolan Emil Ulmeanu1,2 \\ ${ }^{1}$ Spitalul Clinic de Urgență pentru Copii „Grigore Alexandrescu“, București, România \\ Universitatea de Medicină şi Farmacie „Carol Davila“, București, România
}

\begin{abstract}
REZUMAT
Antidiabeticele orale au devenit o etiologie frecvent asociată intoxicaţiilor acute la copil. Studiul realizează o analiză a caracteristicilor demografice, circumstanţiale şi profilului clinic asociat intoxicaţiilor cu antidiabetice orale. A fost realizat un studiu observaţional, descriptiv şi retrospectiv, pe o perioadă de 4 ani, în care au fost incluşi copii confirmaţi cu diagnosticul de intoxicaţie acută cu antidiabetice orale. În lotul studiat, se observă o predominanţă a cazurilor de intoxicaţii acute voluntare la pacienţii de sex feminin la grupa de vârstă 15-18 ani. Analiza etiologică a cazurilor de intoxicaţie acută în lotul studiat a identificat o predominanţă a cazurilor de expunere toxică la antidiabetice din clasa biguanide. Manifestările clinice predominante asociate intoxicaţiilor cu antidiabetice orale au fost în sfera digestivă.
\end{abstract}

Cuvinte cheie: antidiabetice orale, intoxicație acută voluntară, adolescent, manifestări digestive

\section{INTRODUCERE}

Intoxicațiile acute la copil, conform raportărilor Organizației Mondiale a Sănătății, reprezintă una dintre principalele cauze de mortalitate la această categorie populațională, cu peste 3.000 de decese anuale (1). Un studiu epidemiologic național desfășurat în perioada 2006-2010, ce a analizat 6.099 de cazuri de intoxicaţii acute la copii, a concluzionat că etiologia predominant implicată a fost cea medicamentoasă (2).

Antidiabeticele orale devin o etiologie frecventă asociată intoxicațiilor acute la copil ca urmare a creșterii numărului cazurilor de diabet zaharat de tip 2 și, așadar, creșterii utilizării antidiabeticelor. Mecanismele de acțiune ale antiabeticelor orale sunt diferite în funcţie de clasa din care fac parte: sulfornilureicele și meglitinidele stimulează secreția endogenă de insulină, biguanidele și glitazonele măresc activitatea la nivel tisular a insulinei, iar inhibitorii de a-glucozidază scad absorbția la nivel intestinal a carbohidraților (3). Clasele mai noi de antidiabetice orale, precum inhibitorii de dipeptidil peptidază 4, analogii de amilină, agoniștii de glucagon peptid like1, inhibitorii cotransportorului 2 sodiu/glucoză, acționează prin încetinirea golirii gastrice, diminuarea producție de glucagon postrandial, scăderea aportului alimentar și blocarea absorbției glucozei la nivel renal (4). Antidiabeticele orale au fost clasificate în funcție de efectul lor în agenți hipoglicemici, din această categorie făcând parte sulfonilureicele și meglitinidele, și agenți antihiperglicemici, în această categorie fiind incluși biguanidele, glitazonele, inhibitorii de $\alpha$-glucozidază, inhibitorii de dipeptidil peptidază 4, analogi de amilină, agoniști de glucagon peptid like1 şi inhibitorii cotransportorului 2 sodiu/ glucoză (5).

Hipoglicemia este cea mai frecventă manifestare asociată intoxicației cu antidiabetice orale, iar simptomatologia ce o însoțește include manifestări vegetative în sfera digestivă (greață, vărsături, dureri abdominale), cutanată (uriticarie, eritem polimorf), respiratorie (polipnee, hipertensiune pulmonară), cardiovasculară (tahicardie, hipertensiune arterială), 
neurologică (confuzie, agitație, convulsii, comă), musculară (dureri musculare, parestezii) și poate ajunge chiar la insuficiență renală acută și insuficiență multiplă de organe (6-9). Tratamentul intoxicației cu antidiabetice orale presupune aplicarea de măsuri de limitare a absorbției toxicului prin metode de decontaminare gastrointestinală, corectarea hipoglicemiei și a dezechilibrelor electrolitice și acido-bazice și utilizarea tehnicilor de epurare extrarenală $(10,11)$.

\section{OBIECTIVE}

Studiul şi-a propus să realizeze o analiză a caracteristicilor demografice și circumstanțiale ale intoxicațiilor $\mathrm{cu}$ antidiabetice orale la copil pentru a identifica grupele de risc pentru expunerea toxică și pentru a analiza profilul clinic asociat intoxicațiilor cu antidiabetice orale.

\section{MATERIAL ŞI METODĂ}

Studiul de față este unul descriptiv, observațional și retrospectiv, desfășurat în perioada 2014-2018, fiind realizat într-un centrul antitoxic pediatric, secția de Toxicologie-Terapie intensivă a Spitalului Clinic de Urgență pentru Copii „Grigore Alexandrescu“ din București. Lotul studiat este alcătuit din pacienți cu vârste cuprinse între 0 şi 18 ani internați cu diagnosticul de intoxiație acută cu antidiabetice orale.

Criteriile de includere în lot sunt:

- vârsta $<18$ ani

- confirmarea ingestiei de antidiabetice orale voluntar sau accidental, asociate sau nu cu alte substanțe medicamentoase sau nemedicamentoase

- producerea evenimentului în perioada 20142018

- absența altor afecțiuni preexistente.

Criteriile de excludere sunt:

- Vârsta $>18$ ani

- Alt diagnostic decât cel menționat la criteriile de includere

- Prezența altor afecțiuni preexistente

- Producerea evenimentului în afara intervalului de timp 2014-2018
Datele pacienților incluși în lot au fost obținute în urma analizei foilor de observație și au fost consemnate următoarele: vârstă, sex, circumstanțele expunerii, numărul şi tipul de medicamente ingerate, manifestările clinice asociate.

\section{Prelucrarea statistică a datelor}

Datele pacienților incluși în lot au fost analizate utilizând IBM SPSS. Pentru lot au fost calculate medii, mediane și procente.

\section{Probleme de etică medicală}

Etapele alcătuirii lotului de studiu, precum și analiza foilor de observație clinică s-au efectuat în conformitate cu legislația medicală în vigoare.

\section{REZULTATE}

39 de pacienți au fost internați secția de Toxicologie-Terapie intensivă a Spitalului Clinic de Urgență pentru Copii „Grigore Alexandrescu“ din București cu diagnosticul de intoxicație cu antidiabetice orale într-o perioadă de 4 ani (2014-2018).

\section{Analiza demografică}

Pacienții incluși în lotul de studiu au vârste cuprinse între 2 şi 18 ani, media de vârstă fiind de $11,75 \pm$ 5,65 ani, cel mai tânăr pacient internat cu diagnosticul de intoxicație acută cu antidiabetice orale având vârsta de 2 ani. Analiza distribuției pacienților din lotul studiat pe categorii de vârstă evidenţiază un vârf de incidență la categoria de vârstă $15-18$ ani (43,5\%) (Fig. 1).

În lotul studiat, sunt 32 de fete ( $82 \%$ dintre cazurile analizate) și 7 băieți (17,95\%); se constată un raport fete/băieți de 4,5:1.

Din repartiţia pacienților din lotul studiat în funcție de mediul de proveniență, se observă că 13 pacienți $(33,3 \%)$ provin din mediul rural și 26 pacienți $(66,6 \%)$ provin din mediul urban.

Cazurile de intoxicație voluntară au fost mai frecvente în comparație cu cele accidentale, înregistrându-se 29 de cazuri de intoxicație voluntară $(74,36 \%)$

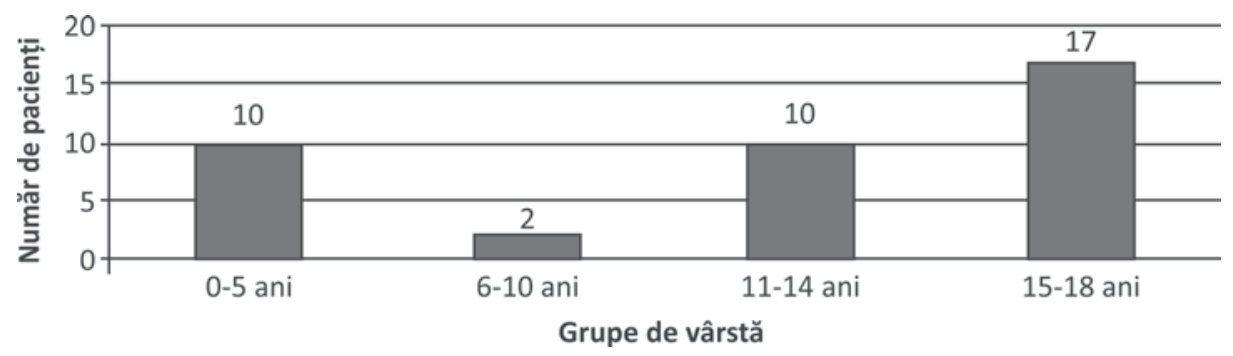

FIGURA 1. Distribuția pe categorii de vârstă 
TABEL 1. Distribuția cazurilor pe grupe de vârstă, sex şi mediu de proveniență

\begin{tabular}{|c|c|c|c|c|c|c|}
\hline $\begin{array}{l}\text { Mediu de } \\
\text { proveniență }\end{array}$ & Sex & $\begin{array}{c}\text { Grupa de } \\
\text { vârstă } \\
0-5 \text { ani }\end{array}$ & $\begin{array}{c}\text { Grupa de } \\
\text { vârstă } \\
6-10 \text { ani }\end{array}$ & $\begin{array}{l}\text { Grupa de } \\
\text { vârstă } \\
11-14 \text { ani }\end{array}$ & $\begin{array}{l}\text { Grupa de } \\
\text { vârstă } \\
\text { 15-18 ani }\end{array}$ & Total \\
\hline Rural & $\begin{array}{c}\text { Feminin } \\
\mathrm{N}(\%) \\
\text { Masculin } \\
\mathrm{N}(\%) \\
\text { Total }\end{array}$ & $\begin{array}{c}1(2,5 \%) \\
0(0) \\
1(2,5 \%)\end{array}$ & $\begin{array}{l}0(0) \\
0(0) \\
0(0)\end{array}$ & $\begin{array}{c}4(7,69 \%) \\
0(0) \\
4(10,25 \%)\end{array}$ & $\begin{array}{c}8(20,5 \%) \\
0(0) \\
8(20,5 \%)\end{array}$ & $\begin{array}{c}13(33,3 \%) \\
0(0) \\
13(33,3 \%)\end{array}$ \\
\hline Urban & $\begin{array}{c}\text { Feminin } \\
\mathrm{N}(\%) \\
\text { Masculin } \\
\mathrm{N}(\%) \\
\text { Total }\end{array}$ & $\begin{array}{l}2(5,1 \%) \\
7(18 \%) \\
9(23 \%)\end{array}$ & $\begin{array}{c}2(5,1 \%) \\
0(0) \\
2(5,1 \%)\end{array}$ & $\begin{array}{c}6(15,38 \%) \\
0(0) \\
6(15,38 \%)\end{array}$ & $\begin{array}{c}9(23 \%) \\
0(0) \\
11(28,2 \%)\end{array}$ & $\begin{array}{c}19(51,28 \%) \\
7(18 \%) \\
26(66,6 \%)\end{array}$ \\
\hline Total & & 10 & 2 & 10 & 17 & 39 \\
\hline
\end{tabular}

TABEL 2. Distribuția cazurilor în funcție de circumstanțele expunerii, caracterul intoxicației şi sex

\begin{tabular}{|l|c|c|c|c|}
\hline Circumstanță & $\begin{array}{c}\text { Caracter } \\
\text { plurimedicamentos }\end{array}$ & $\begin{array}{c}\text { Caracter } \\
\text { unimedicamentos }\end{array}$ & Sex feminin & Sex masculin \\
\hline Voluntar & $26(66,6 \%)$ & $3(7,69 \%)$ & $26(66,6 \%)$ & $1(2,6 \%)$ \\
\hline Accidental & $0(0 \%)$ & $10(25,64 \%)$ & $6(15,38 \%)$ & $6(15,38 \%)$ \\
\hline Total intoxicații & $30(76,9 \%)$ & $9(23,08 \%)$ & $32(28,05 \%)$ & $7(18 \%)$ \\
\hline
\end{tabular}

și doar 10 de cazuri de intoxicație accidentală $(25,64 \%)$.

Analizând lotul studiat în funcție de numărul de medicamente ingerate, se constată că 9 pacienți $(23,08 \%)$ au fost intoxicați cu un singur toxic, iar în cazul a 30 de pacienți $(76,9 \%)$ a fost vorba de intoxicație plurimedicamentoasă (Tabel 2).

Analizând etiologia intoxicației acute cu antidiabetice orale, se constată că majoritatea cazurilor de expunere toxică au fost la antidiabetice orale din clasa biguanide $(n=31$ cazuri, $80 \%), 7$ pacienți $(17,5 \%)$ au ingerat preparate de tip sulfonilureice, iar un singur pacient a fost intoxicat cu antidiabetice orale din clasa meglitinide (Figura 2).

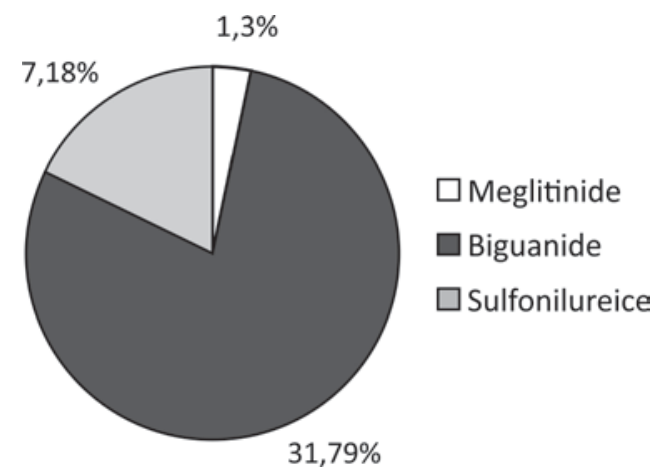

FIGURA 2. Repartiția cazurilor în funcție de etiologia intoxicațiilor

În lotul de studiu, în cazul celor 39 de pacienți, se observă că 30 de pacienți $(56 \%)$ au prezentat manifestări digestive, 20 de pacienți (37\%) au avut manifestări neurologice și doar 4 (7\%) pacienți au avut manifestări cardiace (Figura 3).

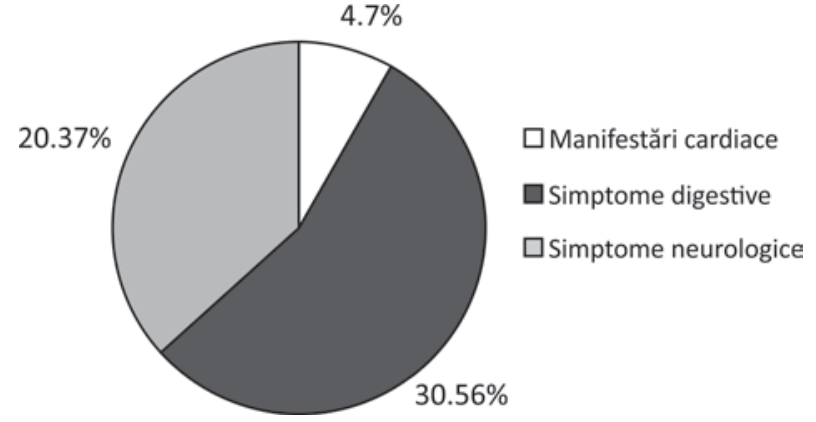

FIGURA 3. Repartitia cazurilor în funcție de simptomatologie

A fost, de asemenea, analizată asocierea manifestărilor clinice și expunerea toxică la medicamente din clasa biguanide și sulfonilureice, remarcându-se o predominanță a manifestărilor digestive asociate intoxicațiilor cu aceste clase de antidiabetice orale (tabelele 3 şi 4).

\section{DISCUȚII}

Intoxicatiile acute $\mathrm{cu}$ antidiabetice orale au crescut ca frecvență în rândul populației pediatrice ca urmare a accesibilităţii crescute la această categorie de medicamente. Analizând cazurile de intoxicație acută ce au fost internate în centrul antitoxic al Spitalului Clinic de Urgență pentru Copii „Grigore Alexandrescu“ din București, am constatat o creștere a prevalenței de $0,8 \%$ a cazurilor de intoxicație acută cu antidiabetice orale în perioada 2014-2018 comparativ cu perioada 2010-2014, fenomen explicat de numărul cres- 
TABEL 3. Analiza prezenței manifestărilor clinice pe grupe de vârstă la pacienții cu intoxicațe cu sulfonilureice

\begin{tabular}{|l|c|c|c|c|}
\hline $\begin{array}{l}\text { Grupe de vârstă } \\
\text { (ani) }\end{array}$ & $\begin{array}{c}\text { Nr. cazuri } \\
\text { manifestări cardiace }\end{array}$ & $\begin{array}{c}\text { Nr. cazuri manifestări } \\
\text { neurologice }\end{array}$ & $\begin{array}{c}\text { Nr. cazuri manifestări } \\
\text { digestive }\end{array}$ & $\begin{array}{c}\text { Total nr. cazuri de } \\
\text { intoxicație }\end{array}$ \\
\hline $0-5$ ani & $0(0)$ & $1(50 \%)$ & $2(100 \%)$ & 2 \\
\hline $6-10$ ani & $0(0)$ & $0(0 \%)$ & $0(0)$ & 0 \\
\hline $11-14$ ani & $1(100 \%)$ & $1(100 \%)$ & $1(100 \%)$ & 1 \\
\hline $15-18$ ani & $1(25 \%)$ & $2(50 \%)$ & $3(75 \%)$ & 4 \\
\hline
\end{tabular}

TABEL 4. Analiza prezenței manifestărilor clinice pe grupe de vârstă la pacienții cu intoxicație cu biguanide

\begin{tabular}{|l|c|c|c|c|}
\hline $\begin{array}{l}\text { Grupe de vârstă } \\
\text { (ani) }\end{array}$ & $\begin{array}{c}\text { Nr. cazuri manifestări } \\
\text { cardiace }\end{array}$ & $\begin{array}{c}\text { Nr. cazuri manifestări } \\
\text { neurologice }\end{array}$ & $\begin{array}{c}\text { Nr. cazuri manifestări } \\
\text { digestive }\end{array}$ & $\begin{array}{c}\text { Total nr. cazuri de } \\
\text { intoxicație }\end{array}$ \\
\hline $0-5$ ani & 0 & $3(37,5 \%)$ & $5(62,5 \%)$ & 8 \\
\hline $6-10$ ani & $1(50 \%)$ & $2(100 \%)$ & $2(100 \%)$ & 2 \\
\hline $11-14$ ani & $2(25 \%)$ & $3(37,5 \%)$ & $7(87,5 \%)$ & 8 \\
\hline $15-18$ ani & $1(7,69 \%)$ & $10(76,9 \%)$ & $11(84,61 \%)$ & 13 \\
\hline
\end{tabular}

cut de adulți diagnosticați cu diabet zaharat de tip 2 ce beneficiază de tratament cu antidiabetice orale şi de accesul facil al copiilor la acest tip de medicamente. În literatura de specialitate, sunt puţine studii în ceea ce privește intoxicația cu antidiabetice orale la copii.

Analizând distribuția pacienţilor pe categorii de vârstă, se constată că cel mai bine reprezentată grupă de vârstă este cea a adolescenților cu vârste de 15-18 ani $(n=17,43,58 \%)$ și o repartiție procentuală egală pentru grupele de vârstă 11-14 ani și 0-5 ani, aceste date fiind în concordanță cu cele din literatura de specialitate. Conform datelor de specialitate, există o predominanță a cazurilor de intoxicație în rândul adolescenților mai ales prin expunerea toxică la substanțe medicamentoase și, conform analizei datelor colectate în centrele antitoxice din Statele Unite, mortalitatea asociată expunerilor toxice înregistrează un maxim la categoria de vârstă 13-19 ani. Conform acestei analize la această categorie de vârstă, în 2019, au fost raportate 86 de cazuri de deces asociate expunerilor toxice, o creștere cu $8 \%$ față de raportările din 2018, iar dintre acestea 71 de cazuri au fost asociate intoxicațiilor medicamentoase (12).

Se constată o predominanță a cazurilor de intoxicație acută voluntară $(n=29,25,64 \%)$ în lotul studiat. Analizând datele în ceea ce privește intenția expunerii toxice în funcție de caracteristici demografice precum sexul, vârsta, mediul de proveniență, constatăm că intoxicațiile voluntare se înregistrează la pacienții de sex feminin și grupa de vârstă 15-18 ani, iar intoxicațiile accidentale se asociază grupei de vârstă 0-5 ani și sexului masculin, confirmând datele din literatură. Un studiu epidemiologic din România ce a analizat cazurile de intoxicație acută la copil în perioada 1997-2000, pe un lot de 11.890 de pacienți internaţi în centru antitoxic al Spitalului Clinic de Urgență pentru Copii „Grigore Alexandrescu“ din
București, a evidențiat o predominanță a cazurilor de expunere toxică accidentală la categoria de vârstă 1-4 ani (65\%) și sex masculin (13).

Datele colectate în centrele antitoxice în Statele Unite ale Americii care au realizat o analiză în ceea ce privește intenția expunerii toxice au constatat că la grupa de vârstă mai mică de 5 ani predomină intoxicațiile accidentale (62\%), iar la categoria de vârstă 13-19 ani au fost mai frecvente intoxicațiile voluntare (26\%) (12).

Analizând lotul studiat din punctul de vedere al caracterului expunerii toxice, se constată că 30 de pacienți au fost diagnosticați cu intoxicație acută plurimedicamentoasă $(76,9 \%)$. Corelând aceste date cu parametri ca sex şi circumstanțe ale expunerii toxice, se identifică o predominanță a cazurilor de intoxicații acute voluntare plurimedicamentoase la pacienții de sex feminin. Un studiu epidemiologic desfășurat în perioada 2006-2010, ce a colectat date din patru centre antitoxice din țară și a analizat 6.099 cazuri de expunere toxică, a concluzionat că cele mai multe cazuri de intoxicații acute au fost cele cu etiologie medicamentoasă, iar majoritatea cazurilor de expunere toxică voluntară (82\%) au fost identificate la pacienți de sex feminin (2).

Analiza etiologică a cazurilor de intoxicație cu antidiabetice orale în lotul studiat a identificat că majoritatea expunerilor toxice au fost cu produse din clasa biguanide $(\mathrm{n}=32,80 \%)$, fapt explicat de utilizarea extensivă a biguanidelor - metformin în monoterapie sau în asociere cu alți agenți antidiabetici orali în terapia diabetului zaharat de tip 2. În 2018, în Statele Unite ale Americii, metforminul a fost al patrulea cel mai recomandat medicament cu peste 83 de milioane de prescripții medicale, fiind cel mai utilizat medicament pentru tratamentul diabetului zaharat de tip 2 (14).

Manifestările clinice asociate intoxicaţiei cu antidiabetice orale au fost predominant digestive $(n=30$, 
$56 \%$ ), iar o analiză a repartiției simptomatologiei clinice în corelație cu etiologia expunerii toxice a identificat în lotul studiat că atât în cazul intoxicației cu biguanide, cât și în cazul intoxicației cu sulfonilureice au predominat manifestrările clinice în sfera digestivă, ceea ce concordă cu datele din literatură. Intoxicația cu antidiabetice orale de tip sulfonilureice conduce către apariția hipoglicemiei, care se poate exprima clinic prin manifestări digestive de tip greață, vărsături, dureri abdominale. Review-urile de specialitate au identificat o incidență crescută a utilizării metforminului și apariția simptomatologiei digestive (15). Datele colectate de centre regionale antitoxice din Statele Unite Ale Americii în ceea ce privește cazurile de intoxicație acută cu metformin au arătat că, în cazul celor 55 de pacienți cu intoxicație acută cu metformin, manifestările clinice au fost di-

Conflict of interest: none declared

Financial support: none declared

\section{BIBLOGRAFIE}

1. Dinesh S, Towner E, Vincenten J, Segui-Gomez M, Racioppi F. European Report on Child Injury Prevention. Available at: http://www. who.int/violence_injury_prevention/child/injury/world_report/ European_report.pdf.

2. Ulmeanu C, Nițescu V, Bizo A, Gafencu M, lordache C, Jitareanu C. Epidemiologia intoxicațiilor acute la copil în România - studiu multicentric pe 5 ani. Congresul Național de Pediatrie,; București, 2011.

3. Meneses MJ, Silva BM, Sousa M, Sá R, Oliveira PF, Alves MG. Antidiabetic Drugs: Mechanisms of Action and Potential Outcomes on Cellular Metabolism. Curr Pharm Des. 2015;21(25):3606-20.

4. Defronzo RA, Ferrannini E, Keen H, Zimmet $P$ (eds.). International Textbook of Diabetes Mellitus, vol. 2. Jon Wiley \& Sons 1992;773-791.

5. Lorenzati B, Zucco C, Miglietta S, Lamberti F, Bruno G. Oral Hypoglycemic Drugs: Pathophysiological Basis of Their Mechanism of Action Oral Hypoglycemic Drugs: Pathophysiological Basis of Their Mechanism of Action. Pharmaceuticals (Basel). 2010; 3(9):3005-3020.

6. Seltzer HS. Drug-induced hypoglycemia: a review of 1418 cases. Endocrinol Metab Clin North Am. 1989;18:163-83.

7. Haymond MW. Hypoglycemia in infants and children. Endocrinol Metab Clin North Am. 1989;18:211-52.

8. Field JB. Hypoglycemia: definition, clinical presentations, classification, and laboratory tests. Endocrinol Metab Clin North Am. 1989;18:27-43 gestive de tipul greaţă (2 pacienţi), diaree (2 pacienți) (16).

\section{CONCLUZII}

Intoxicațiile acute $\mathrm{cu}$ antidiabetice orale au potențialul de a evolua către forme severe cu letalitate mare, mai ales dacă evoluează către forme cu insuficiență renală acută sau acidoză lactică refractară.

Prevalența în creștere a acestui tip de intoxicație acută în rândul populației pediatrice semnalează necesitatea iniţierii unor campanii de informare în ceea ce privește potențialul toxic al acestor medicamente, precum și reglementarea unor măsuri de limitare a accesului pacienților pediatrici la medicamente din clasa antidiabeticelor orale.

9. Cryer PE. Hypoglycemia: pathophysiology, diagnosis, and treatment. Oxford: Oxford University Press; 1997.

10. Ghannoum M, Gosselin S. Enhanced poison elimination in critical care. Adv Chronic Kidney Dis. 2013;20(1):94-101.

11. American Academy of Clinical Toxicology, European Association of Poisons Centres and Clinical Toxicologists. Position paper: single-dose activated charcoal. Clin Toxicol. 2005;43(2):61-87.

12. Mowry JB, Spyker DA, Brooks DE, McMillan N, Schauben JL. 2014 Annual Report of the American Association of Poison Control Centers' National Poison Data System (NPDS): 32nd Annual Report. Clin Toxicol (Phila). 2015;53(10):962-1147.

13. Nițescu V. Afectarea hepatică și renală în intoxicațiile acute medicamentoase la copil. Protocoale terapeutice. Teză de doctorat. București: UMF „Carol Davila“, 2007.

14. Holman R. Metformin as first choice in oral diabetes treatment: the UKPDS experience. Journ Annu Diabetol Hotel Dieu. 2007:13-20.

15. McCreight LJ, Bailey CJ, Pearson ER. Metformin and the gastrointestinal tract. Diabetologia. 2016;59(3):426-435.

16. Spiller HA, Weber JA, Winter ML, Klein-Schwartz W, Hofman M, Gorman SE, Stork CM, Krenzelok EP. Multicenter case series of pediatric metformin ingestion. Ann Pharmacother. 2000 Dec;34(12):1385-8. 